\title{
El canon femenino en las obras de Josefa Amar y Borbón
}

\author{
Ernesto Viamonte Lucientes \\ I.E.S. Molina de Aragón
}

Resumen:

Es el propósito de este trabajo establecer el modelo de mujer que se desprende de los escritos de una de las ilustradas hispanas más notables, doña Josefa de Amar y Borbón (1743-1793), definiendo su alcance al compararlo con algunas de las ideas que al respecto circulaban en su tiempo.

Para extraer tal canon me fijo, fundamentalmente, en dos trabajos de Amar y Borbón en los que volcó su atención acerca de la educación femenina: Discurso sobre la educación física y moral de las mujeres y Memoria para la admisión de señoras... que dirigió a la Sociedad Matritense.

De ambos textos se desprenden unas ideas que se balancean entre la innovación y el tradicionalismo, donde la educación se entiende como valor indiscutible, ya que su ausencia conlleva falta de oportunidades, pero que siempre está en función de la condición y del talento de cada mujer.

Ahora bien, al comparar las ideas de nuestra autora con otras que sobre tal particular eran comunes en la España de su tiempo —una España donde los reformistas eran siempre minoría, donde sólo el $15 \%$ de las mujeres estaba alfabetizada, donde la educación estaba en manos religiosas con lo que ello supone y donde hasta incluso las elites ilustradas podían pasar del lado de la reacción en algunos temas_-, asoma una Amar y Borbón por delante de su momento y en sintonía con los ilustrados patrios más avanzados.

Palabras clave:

Josefa Amar y Borbón. Mentalidades. Literatura.

CES.XVIII, núm. 15 (2005), págs. 311-328. 
Josefa Amar y Borbón fue una mujer singular que hoy sigue siendo una figura atractiva por varios motivos. Entre ellos destaca su interés por vertientes del saber consideradas «poco femeninas». Sirvan como ejemplo su traducción de la obra de Francisco Griselini, Discurso sobre el problema de que corresponde a los párrocos y curas de las aldeas el instruir a los labradores en los buenos elementos de la economía campestre... ${ }^{1}$, o su ocupación en una Aritmética espa$\tilde{n} o l a^{2}$. El dato nos pone sobre la pista, más allá de lo anecdótico, de la idea que doña Josefa tenía de sí misma, y por ende de la condición femenina —o cuando menos de algunas mujeres-. Una idea bastante más avanzada de lo que en un principio pueda parecer al leer sus escritos desde la perspectiva de este siglo, y que sólo se pone al descubierto si se engarza su pensamiento con las mentalidades del tiempo en que se gestó. Establecer el modelo de mujer que se desprende de los escritos de Amar y Borbón y compararlo con algunas de las ideas que al respecto eran comunes en su tiempo es el propósito del presente trabajo.

De las empresas en las que estuvo embarcada doña Josefa sólo nos quedan unas cuantas obras. Dos de ellas son básicas para rastrear el canon de mujer que anhelaba su autora: el Discurso en defensa del talento de las mujeres y de su aptitud para el gobierno y otros cargos en que se emplean los hombres ${ }^{3} \mathrm{y}$, en especial, el Discurso sobre la educación física y moral de las mujeres. ${ }^{4}$. Hay otros trabajos de la ilustrada relativos al tema pero que, bien por su mínimo calado, como ocurre en el caso de la Oración Gratulatoria... dirigida a la Junta de Señoras en $1787^{5}$, bien porque no se hallan localizados, como ocurre con dos entradas dadas por Palau, Importancia de la instrucción que conviene dar a las mujeres y Ramillete de escogidos consejos que la mujer debe tener presentes en la vida del matrimonio ${ }^{6}$, no pueden aportar nada a la elaboración del canon femenino concebido por nuestra autora. Eso sí, la sola mención de los títulos demuestra el gran interés que por todo lo concerniente a las mujeres tenía doña Josefa, pues, pese a la variedad de inquietudes arriba señaladas, la mujer y sus condiciones son temas recurrentes en gran parte de sus trabajos.

Zaragoza, Blas Miedes, 1783.

2 La información sobre este texto nos la proporciona Félix de LATASSA en su Biblioteca nueva de escritores aragoneses, Pamplona, Joaquín de Domingo, 1801.

3 Memorial Literario, Tomo VI, 1786, pp. 400-430. La reproduce Olegario Negrín en Ilustración y educación. La Sociedad Económica Matritense, Madrid, Editora Nacional, 1984, págs. 162-176, que es la edición que utilizo en citas.

4 Madrid, B. Cano, 1790. Cito por la edición de M.V. López Cordón, Madrid, Cátedra, 1994.

5 Madrid, Sancha, S.A. y también en Memorial Literario, tomo XII, 1787, págs. 588-592.

6 Véase A. Palau, Manual del librero hispanoamericano, Barcelona, Librería Palau, 1956, entradas 10720 y 10721. 
De todos ellos la aportación más valiosa, tanto de su autora como para nuestros propósitos, es el Discurso sobre la educación física y moral de las mujeres. Él ha de ser el cañamazo sobre el que bordemos estas líneas. Es obra dividida en dos partes, amén de un prólogo: «De la educación física» y «De la educación moral». Un simple vistazo nos pone de inmediato sobre la pista de a qué concede mayor importancia su creadora: mientras a la primera parte le dedica VIII apartados, a la segunda le consagra más del doble, concretamente XVII. Incluso lo dice explícitamente:

La educación moral es sin duda la más difícil, pero también la más importante, porque abraza la enseñanza e ilustración del entendimiento, la regla y la dirección de las costumbres, y en una palabra lo que se llama buena conducta y manejo en todas las acciones?

Esta atención a lo moral me parece que es una de las grandes aportaciones del pensamiento de doña Josefa.

Por las páginas del Discurso pasan las diversas edades y condiciones de la mujer, dentro de las pocas posibilidades que la sociedad de la época podía ofrecerle a lo largo de su vida. En tan totalizadora trayectoria aparece un modelo de mujer que es, desde luego, el deseado por Amar y Borbón y, hasta cierto punto, al que aspiran sus compañeros de desvelos. Veamos, por lo tanto, en qué consiste tal pretensión.

En primer lugar hay que delimitar claramente el que doña Josefa entendía como campo de acción de las mujeres:

En [las] familias privadas tienen las mujeres su particular empleo. Éste es la dirección de la casa, el cuidado y crianza de los hijos, y sobre todo la íntima y perfecta sociedad con el marido ${ }^{8}$.

¿Decepcionante? Es posible. Pero por eso hay que atender a lo anteriormente dicho: a la conexión de estas ideas con la habituales en su tiempo. Un poco de paciencia, por lo tanto. Porque doña Josefa, como tantas de sus contemporáneas, tal vez porque no les quedaba otro remedio, es persona sutil. Y así, poco a poco, va ganando terreno y nos dice:

Un hombre ocupado todo el día en negocios, muchos de ellos desagradables, mira su casa y familia como el centro de su descanso [...] Este descanso y alivio

7 Amar y Borbón, Discurso sobre la educación, pág. 135.

$8 \quad$ Ibid., pág. 63. 
será completo si tiene una mujer apacible y discreta con quien confiar sus secretos y alternar en una conversación racional ${ }^{9}$.

Es cuestión de ir sumando, pero con números enteros: la mujer ha sido presentada en sociedad con el marido, pero para que esto se produzca perfectamente la mujer ha de ser cultivada. Ahora bien, ¿podía una fémina recibir tal educación? La respuesta natural es sí. Pero reformularé la pregunta: ¿podía una mujer recibir una educación similar a la de un hombre? Aquí la respuesta cambia de signo y se llena de matices. Amar y Borbón, sin embargo, escribe una página al respecto que es un modelo de diplomacia. Merece la pena detenerse en ella.

La ilustrada, hablando de la educación de los vástagos, comienza el apartado haciendo un elogio de lo importante que es usar rectamente las facultades racionales e implicarlas en la muy ilustrada idea de la felicidad. Luego pasa a hablar de lo complicado que resulta acertar con tal uso y dice:

pues unas veces por ignorancia de los padres, otras por incapacidad o mala índole de los hijos, parece vano e inútil todo el trabajo. La misma variedad que se advierte en los rostros suele haberla en los ingenios e inclinaciones ${ }^{10}$.

Obsérvese la indistinción, la referencia y utilización de hijos, con el género no marcado, palabra con la que, burla burlando, coloca en la infancia, para no molestar, esa igualdad de capacidades, o, como dice la autora, de ingenios. Es un primer paso que conducirá al lógico y esperado, pero para el que ha de contar —nuevo rasgo de sutileza — con apoyos, con la apelación a la autoridad: «Jenofonte — dice- establece por regla que la aptitud e ingenio de las mujeres no cede al de los hombres si se cultiva y fortalece» ${ }^{11}$. Era natural que, dada una igualdad inicial, las diferencias se produjesen por los factores que aparecen a lo largo de la vida de cada uno. Lo dice bien claro Amar y Borbón que, aunque admite que hay rasgos más propios bien de hombres, bien de mujeres, en general todo «depende de la fragilidad de la naturaleza, de los vicios de una mala educación, del mayor o menor influjo de la reflexión, del ejemplo, de las circunstancias en que cada uno se halla, y de otras causas morales y físicas, que son comunes a entrambos sexos» ${ }^{12}$. No hay, por lo tanto, grandes diferencias basadas en el sexo. Éstas vienen dadas por otros factores el más influyente de los cuales es, para la ilustrada, el de la diversa educación recibida. De ahí que el leit motiv de su escrito sea «que el bello

\footnotetext{
$9 \quad$ Ibid., pág. 74.

$10 \quad$ Ibid., pág. 135.

11 Ibid., pág. 179.

12 Ibid., pág. 205.
} 
sexo [estime] la intención que ha gobernado la pluma, la cual ha sido excitarla a la aplicación y cultura para aumentar sus gracias y hacerlas más permanentes» ${ }^{13}$.

Sin embargo, donde sorprende doña Josefa — repito una vez más, si no se conectan sus ideas con el tiempo en el que se elaboraron-, es al dar como factor diferenciador la distinta pertenencia social. La autora afirma sin ambages que, aunque un sistema de educación debería comprender toda clase del estado, tal idea es inviable. Así, a las mujeres que la ilustrada llama «de la clase común» les reserva, simplemente, conocer los oficios mecánicos de la casa, pues al estar casadas con hombres rudos no son precisos ciertos adornos reservados para condiciones más altas ${ }^{14}$. La idea puede llamar la atención, pero en absoluto es ajena a su tiempo. Primero, porque tiene como mira un pragmatismo, siempre unido a la idea de utilidad, bien caro a los precursores de las Luces; segundo, porque no hay sino recordar, entre otras muchas, afirmaciones como las de Jovellanos y su veto al «pueblo que trabaja», que necesita diversiones, pero no espectáculos, en su Memoria para el arreglo de la Policía de los Espectáculos y diversiones públicas $y$ sobre su origen en España ${ }^{15}$.

De lo visto hasta ahora se desprende que lo que verdaderamente cuenta para nuestra autora es el talento, que se había de cultivar, y la pertenencia a una cierta posición social, que en una sociedad sumamente inmovilista venía dada. Valores que doscientos años después pueden parecer alicortos, pero que, en su momento, se colocaban a la avanzadilla, ya que hay que tener en cuenta que el factor talento era negado para las mujeres por la mayoría de la población del dieciocho hispano. Y esto es a lo que no renuncia doña Josefa, antes bien se detiene, con morosidad, en su necesario cultivo.

Que la autora del Discurso físico y moral no es ninguna revolucionaria es evidente. En realidad ningún ilustrado español lo fue. «No formemos un plan fantástico — dice-: tratemos sólo de rectificar en lo posible el que está ya establecido» ${ }^{16}$. López Torrijo, en «El pensamiento pedagógico ilustrado sobre la mujer en J.A.B.», califica las ideas de Amar y Borbón como «una peculiar mezcla de innovación y tracionalismo» ${ }^{17}$. Tradicionalismo, fundamentalmente, en considerar el matrimonio como eje, innovación en dar más importancia a la educación moral que a la física. Y así se va balanceando entre una y otra postura. Es por

13 Ibid., págs. 267-268.

$14 \quad$ Ibid., pág. 73.

15 G.M. de Jovellanos, ob. cit., vol. II, Madrid, Espasa-Calpe, 1975, págs. 7 y ss.

16 Amar y Borbón, Discurso sobre educación, pág. 72.

17 Véase M. López TorRijo, «El pensamiento pedagógico ilustrado sobre la mujer en J.A.B.», Educación e Ilustración en España. III Coloquio de historia de la educación, Barcelona, Universidad de Barcelona, 1984, págs. 114-129. 
lo tanto natural que piense que haya de prevalecer, en el cultivo de cualidades propias de la mujer, lo que doña Josefa llama «la labor de manos, la economía y el gobierno doméstico», a la par que no ve oposición a que las mujeres cultiven su entendimiento, algo que es conveniente a todos ${ }^{18}$, ya que - y aquí topamos con una idea clave de la Ilustración- «siempre es útil al que [lo] posee y a los demás con quienes ha de tratar: al que [lo] posee, porque le proporciona los medios de emplear el tiempo con fruto: y a los demás, porque encuentran en su trato la satisfacción y contento que produce la instrucción y civilidad» ${ }^{19}$. Y en todo caso porque con ello se evita la ociosidad «tan perjudicial en las mujeres como en los hombres» ${ }^{20}$.

Pero ¿qué habilidades estima la autora del Discurso que son propias de las mujeres? En principio, y no es tontería, aquéllas para las que muestra una mayor capacidad. Ese es el baremo que tiene coda: que se promuevan entre ellas las más útiles ${ }^{21}$. Y ¿̨ónde ha de producirse este fomento? Pues Amar y Borbón insiste, en muchas partes de su trabajo, que es en el hogar familiar, que ha de ser la madre — una mujer-, la que con el ejemplo — idea clave de nuestra ilustrada-, eduque a las hijas, salvo a aquéllas que no reuniesen las calidades adecuadas; entonces sí que recomienda encomendar la educación a alguna orden religiosa o a un aya suficientemente preparada ${ }^{22}$. Pero la aragonesa se percata de que está entrando en un círculo cerrado, porque ¿¿dónde están esas damas instruidas? Complicado. Es necesario que el gobierno se ocupe de tal fomento. En todo caso, sea la progenitora o sea un agente externo al hogar, la educación de la niña ha de regirse por dos elemento básicos: el método y el ejemplo.

Sobre el método, que nunca será rígido y siempre prudente ${ }^{23}$, incide doña Josefa varias veces durante el Discurso. Pero más allá de detalles disciplinarios y consejos varios, lo que interesa de la programación es que ésta habrá de contar con cinco tiempos: de devoción, de labor, de lección, de tratar con las gentes y de honesta diversión. Tales han de ser las facetas que se habrán de cultivar para formar una verdadera mujer.

El ejemplo es motivo recurrente a lo largo de la obra, entendido como la mejor táctica persuasoria. Ver a una madre económica, aplicada, modesta, en armonía con su marido, dice ser la lección muda más profunda ${ }^{24}$. Una vez más

\footnotetext{
18 Amar y Borbón, Discurso sobre educación, págs. 160, 164-165, 170.

19 Ibid., pág. 187.

Ibid., pág. 189.

Ibid., pág. 194.

Ibid., págs. 244-245 y 248.

Ibid., págs. 187-188.

24 Ibid., pág. 137.
} 
entramos en ese círculo cerrado antes señalado: las mujeres, las bien educadas, han de educar a las mujeres.

Y ¿qué cualidades han de adornar a las féminas? ¿Qué modelo de mujer propugna Amar y Borbón? Pues una mujer que, sin desatender las gracias que no dan la verdadera felicidad, es decir, las gracias superfluas, adquiera otras más sólidas, compañeras de todas las edades, útiles a su poseedora y a las gentes que a la misma traten, en una palabra, las gracias del entendimiento. Cultivo que, en la mujer, no encuentra otro estímulo que la satisfacción propia.

Vemos, por lo tanto, que, pese a primar lo moral, la autora atiende a otros muchos factores, y que también en el cultivo de la mujer se han de tener en cuenta los tiempos que en su programa llamaba de diversión honesta y de trato con los hombres ${ }^{25}$. Aparte del cuidado de la salud, que ha de estar siempre presente, aun antes del alumbramiento, también se ha de realzar el físico de cada uno, se ha de tener siempre presente la limpieza, se ha de atender a las apariencias — «La vergüenza es prensa tan recomendable en las mujeres que conviene fomentarla y mantenerla a cualquier precio» ${ }^{26}$, si bien critica, incluso de una manera vehemente, la distinción que se usa al presentarse ante la gente con mucha pompa, siendo desidia todo lo que incumbe a lo interior, cuando — dice- «la limpieza y la decencia sientan bien a todas horas» ${ }^{27}$. Un programa de educación completo que ha de abarcar también las diversiones. Así, aunque el tiempo «no es justo se emplee todo en visitas y paseos», o en acercarse a las comedias, es obvio que estos entretenimientos estarán entre los usuales de las mujeres. A los primeros no pone otra restricción que la del tiempo: no estar a todas horas en paseos y visitas. La frecuentación de las comedias sólo se hará si en ellas hay «poco o nada de amores» ${ }^{28}$. Engarza este particular con la tan traída crítica del lujo, propugnando que cada uno ha de vestir conforme a las circunstancias y a sus circunstancias, teniendo en cuenta su situación social, huyendo de la afectación y del envanecimiento ${ }^{29}$.

Ahora bien, si es cierto que la autora del Discurso se interesa por esos cinco tiempo referidos, no lo es menos que en su prelación los últimamente descritos ocupan menos su atención. Entre los cinco hay que notar que el que aparece en primer lugar es el dedicado a la devoción. La religiosidad es cualidad inherente

25 Ibid., págs. 80, 83 y 127.

26 Ibid., pág. 142.

27 Ibid., pág. 201.

28 Ibid., págs. 160 y 185.

29 Recuérdese al respecto la idea propugnada por P. Fernández Quintanilla de uniformar a las mujeres para evitar los problemas derivados del lujo y del querer aparentar. Véanse al respecto ibid., págs. 197, 199 y 202, y la muy oportuna anotación de López Cordón, pág. 199. 
al modelo de mujer diseñado por Amar y Borbón. En primer lugar porque para ella la instrucción cristiana es necesaria tanto a niños como a niñas ${ }^{30}$. Lo cual no impide que su idea de la religiosidad esté en sintonía con las características más comunes que sobre este particular tenían los ilustrados españoles. Así, la zaragozana aboga por una religiosidad que se practique lejos de lo meramente externo, que consista en «practicar lo bueno y aborrecer lo malo, en refrenar pasiones, en mortificar apetitos, en el ejercicio de la caridad, y sobre todo en el fiel cumplimiento de obligaciones. Todo lo cual puede hacerse sin salir de casa, y aun sin que lo adviertan los demás ${ }^{31}$. Ideas filojansenistas, como ha estudiado Mc Clendon ${ }^{32}$, que se ponen más abiertamente de manifiesto al hablar de la opción de tomar estado religioso, elección sólo admitida si de por medio hay una sólida vocación, pero nunca motivada por circunstancias externas. En suma, cumple con los preceptos máximos de la religión aquel que, casado o religioso, cumple con sus obligaciones respectivas ${ }^{33}$. Porque otro particular que hay que tener en cuenta es que, para doña Josefa, las mujeres sólo tienen dos posibles estados como opción: el de monja o el de casada, ya que una soltera, en sus mismas palabras, «es un cero» que nunca puede hacer ni lo que las casadas ni lo que las monjas ${ }^{34}$.

No obstante, es evidente, cuando se lee el Discurso, que, de los cinco tiempos dedicados a la educación de la mujer, los principales son los de la labor y los de la lección. Dicho ha quedado, y lo repite la autora varias veces, que las ocupaciones fundamentales de las mujeres son la dirección y el gobierno de la casa, el cuidado y crianza de los hijos y la más cercana sociedad con el marido. Tales empleos abarcan toda condición social ${ }^{35}$. Para realizar tales tareas con perfección, los cimientos en que debe basarse el modelo de mujer que propugna Amar y Borbón son el ahorro y el orden ${ }^{36}$. En la educación de los hijos la base es el respeto y la obediencia, siempre buscando el término medio entre la contemplación excesiva y el rigor ${ }^{37}$. Por lo que respecta a la comunión con el marido, el matrimonio es formulado — no podía ser de otra manera- como eterno ${ }^{38}$, ideal si se produce —otras ideas bien conocidas—entre iguales y si se cuenta con las

$30 \quad$ Ibid., pág. 148.

31 Ibid., pág. 150.

32 C.C. McClendon, «Neojansenist Elements in the Work of Josefa Amar y Borbón», Letras Femeninas, 7 (1981), págs. 41-48.

33 Amar y Borbón, Discurso sobre la educación, págs. 226-227.

34 Ibid., págs. 225-226.

5 Ibid., pág. 162.

6 Ibid., pág. 168.

37 Ibid., págs. 218, 219 y 222.

$38 \quad$ Ibid., pág. 228. 
voluntades de las hijas ${ }^{39}$. En cuanto al trato con el marido, se trata de distribuir con prudente economía los intereses del cónyuge — en un matrimonio donde los bienes han de ser comunes-, cuidar de los hijos, casa y familia, además de aliviar con la presencia la carga de los empleos del marido ${ }^{40}$. Prudente y agradable son las calidades que habrá de reunir.

Por lo que respecta al tiempo dedicado a la lección, ya han sido señalados los dos factores que lo marcan: talento y condición social, si bien el aprendizaje de lectura y escritura sobrepasa ambos condicionantes. A partir de ahí, cumpliendo ambos requisitos, la mujer puede acercarse a toda ciencia y arte y adelantar sus conocimientos a cualquier materia que le agrade ${ }^{41}$ : lengua nativa, filosofía, historia, aritmética, lenguas griega y latina, lenguas vivas, geografía e incluso otras disciplinas consideradas menores, siempre que su talento se sienta inclinado hacia ellas, como son el dibujo, la música o el baile.

Para terminar esta primera parte, me gustaría detenerme en las prendas que deben adornar a toda mujer que se precie, así como en los vicios de los cuales debe huir. De todo ello se ocupa también la autora del Discurso que advierte que, aunque toda generalización es mala, sí es cierto que hay cualidades y defectos más propios, bien de hombres, bien de mujeres. La mujer ha de evitar la lisonja — gran defecto y peligro que puede llevarle a ser burlada-, ha de evitar el exceso de locuacidad — que imputa a defectos de educación—, la curiosidad - vicio al que se le puede dar la vuelta y convertirlo en virtud, si se encamina hacia las cosas útiles—, y también ha de apartarse del «vicio de las hablillas» y de los excesos — con la reflexión y el juicio como antídotos— ${ }^{42}$. Por el contrario, ha de cultivarse en la mujer la modestia, la moderación, el adecuado comportamiento, tanto íntimo como social, así como la honestidad, entendida fuera de toda connotación moral.

En el resto de obras apenas aporta doña Josefa nada nuevo al canon de la mujer que se desprende del Discurso. No obstante, un repaso de su Memoria para la admisión de señoras... en la Matritense, nos sirve para reafirmar las ideas claves en el modelo de mujer que propugna nuestra ilustrada.

La Memoria se abre con el tema clave en la obra de Amar y Borbón: la importancia de la instrucción y el lamento por no haber un establecimiento público que se dedique a la educación femenina ${ }^{43}$. La autora parte de la igualdad física de hombres y mujeres, «sin negar por esto las excepciones que convienen a cada

39 Ibid., págs. 229 y 231.

$40 \quad$ Ibid., págs. 234-235.

${ }_{41}$ Ibid., pág. 178.

$42 \quad$ Ibid., págs. 206-211 y 221.

43 J. Amar y Borbón, Memoria, pág. 162. 
sexo» ${ }^{44}$, y se duele especialmente de que todavía se dispute sobre el talento y capacidad de las mujeres, algo que admiten tanto hombres como mujeres ${ }^{45}$. Divide a éstas en esclavas y dependientes, las que habitan en un mundo incivilizado y civilizado, respectivamente. Las segundas centran el resto del escrito y, aunque libres, dice que son tratadas por los hombres como seres inferiores ${ }^{46}$. Tras una digresión bíblica pueril — con la curiosidad de Eva como elogio del ¿̀viciovirtud? de la curiosidad - , comienza lo mejor de su razonamiento: los hombres no son iguales, tienen talentos diversos; con la mujeres ocurre otro tanto. ¿En qué radica la diferencia entre hombre y hombre o mujer y mujer?: en la creación. $¿ Y$ entre hombres y mujeres?: en las oportunidades. E ilustra lo mantenido con diversos ejemplos de la historia. De tales ilustraciones, precisamente, derivan una serie de requisitos importantes en las mujeres, que ya nos son conocidos, y que son, básicamente, la prudencia y el valor ${ }^{47}$. A la conclusión que llega esta primera parte de la Memoria es que todo es un problema de educación. Se queja de que las niñas sólo sean instruidas en leer, escribir y alguna habilidad manual, amén de en adornarse. Si una mujer se decanta por los estudios se convierte en una auténtica heroína que sólo encontrará trabas y nunca estímulos ${ }^{48}$.

La segunda parte de la obra se centra ya en el debate que se produjo en el seno de la Matritense. Doña Josefa, tras una introducción sobre el particular, refuta las ideas mantenidas por Cabarrús, el gran contrario a la admisión de mujeres. Desde luego, comparte con él que no todas las damas deban entrar a la Sociedad, como no deben entrar todos los caballeros, pero rechaza que no puedan ser aceptadas aquéllas que cumplan ciertos requisitos ${ }^{49}$. Niega imputaciones generalizadoras, como el que todas las mujeres no sean discretas, y rechaza la separación de sexos en las Juntas, idea que, para ella, habla muy poco de la estima del detractor tanto hacia las mujeres como hacia los hombres ${ }^{50}$. Por último, no admite tampoco el que sea argumento para no acogerlas su falta de conocimientos. Razona que también muchos hombres carecen de ellos y que en según qué particulares las mujeres pueden sobrepasar a los varones. Incluso llega a manifestar que hay cualidades notables en las señoras: «la mayor facilidad con que se imponen en los asuntos y por los primeros pensamientos oportunos que suelen tener para resolver con ventaja ciertas dificultades ${ }^{51}$, amén de poder contribuir

\footnotetext{
$4 \quad$ Ibid., pág. 162.

Ibid., pág. 162.

Ibid., págs. 163-165.

Ibid., págs. 167-168.

Ibid., págs. 168-169.

Ibid., págs. 170-171.

Ibid., págs. 172-173.

Ibid., pág. 173.
} 
con los gastos de la Sociedad. Y si bien admite que el lujo excesivo es ocasionado frecuentemente por las mujeres, asunto que tanto preocupó a los Amigos del País, no es menos evidente que con el ejemplo que se vería en la Económica, —otra vez más la importancia del ejemplo-, se podrían corregir tales excesos ${ }^{52}$. Tras agradecer su posición a los socios que han apoyado la admisión y pidiéndola ella abiertamente, cierra el escrito enumerando una serie de virtudes propias de las mujeres, como es su mayor inteligencia para promover trabajos relacionados con los hilados, tejidos y encajes «y todas las labores propias del bello sexo» ${ }^{53}$.

¿En qué consiste, por lo tanto, el canon femenino propuesto por doña Josefa Amar y Borbón? Primero en una visión de la condición de las mujeres de su tiempo tremendamente deprimente. Recordemos que para la ilustrada o se era lo que ella llama esclava o, en el mejor de los casos, dependiente. Que esta condición tiene su raíz en una falta de atención social hacia la educación femenina, que se traduce en una falta de oportunidades, ya que a una de esas mujeres dependientes sólo le cabían dos alternativas: esposarse o abrazar la religión. La segunda vía sólo la concibe desde una sincera vocación; la primera admite categorías. Si una mujer pertenece a lo que Amar y Borbón llama «clase común», sólo ha de ser adiestrada en los oficios mecánicos de la casa, mientras que una mujer de más alta condición puede ser cultivada en otros menesteres. Todo está en función de unas ideas pragmáticas, propias de la época, donde el hombre —en masculino singular-, sigue siendo la medida de todas las cosas. Porque si una mujer ha de ser cultivada según su condición y talento, lo ha de ser en función de adecuarse a su marido, ya que el matrimonio ha de darse entre iguales - y abárquense aquí todas las variedades posibles-. Y recordemos que el principal empleo de la mujer, repetido constantemente en las obras de la zaragozana, es la dirección y gobierno de la casa, cuidado y crianza de los hijos y la sociedad más perfecta posible con el marido. En esto último es donde entra el educarse o no, ya que - lo llega a afirmar explícitamente—, ¿qué necesidad tiene de ello la mujer casada con un hombre rudo? Ahora bien, en el caso de que el marido tenga ingenio, la mujer habrá de intentar aproximarse a su nivel, porque doña Josefa no admite la discusión sobre la incapacidad y la falta de talento generalizado en las mujeres. Es más, lo que admite es, incluso, la mayor habilidad para ciertas labores. Es entonces, una vez que se reúnan los dos requisitos indispensables, talento — sólo cuestionado individualmente—, y posición social, cuando la importancia de la educación es capital. Educación que trabaja sobre el talento de cada uno de manera que sea útil para el individuo particular y para la colectividad. Talento

$52 \quad$ Ibid., pág. 174.

53 Ibid., pág. 175. 
que, en su realce, tiene a la madre como gran estímulo y ejemplo y que ha de trabajarse en cinco direcciones:

a) Devoción: en donde la mujer ha de practicar lo bueno y aborrecer lo malo, ejercer la caridad y, sobre todo, cumplir con sus obligaciones.

b) Trato con las gentes: realzando su físico, cuidando de la limpieza, vistiendo sin afectación conforme a su condición y circunstancias.

c) Diversión honesta: con razonables visitas y paseos y manteniendo el decoro.

d) Labores: con las vistas atingentes a casa, hijos y marido.

e) Lección: con la condición social y el talento como ejes, si bien la lectura y escritura superan tales condicionantes y pudiéndose acercar a toda arte o ciencia quien cumpla ambos requisitos.

No se ha de descuidar, en suma, ni las gracias más efímeras ni las más perdurables, fomentando una serie de virtudes como el ahorro, la reflexión o el juicio, el orden, el valor, la prudencia, la modestia, la moderación, la discreción, huyendo del gusto por la lisonja, el exceso de locuacidad y tornando la curiosidad en virtud.

Porque, se ha visto, no hay diferencias generales de ingenio entre hombres y mujeres; las hay individuales, entre hombres y hombres, mujeres y mujeres, y también entre mujeres y hombres. Pero disimilitudes que se basan en el carácter y la condición de cada uno, en la influencia de la reflexión y en los ejemplos recibidos, en las circunstancias, en las oportunidades y en otros factores, el más importante de los cuales es el de la educación. Elemento sobre el que una y otra vez Amar y Borbón enfatiza su determinante importancia.

Y ahora volvamos a algo ya apuntado. Una vez visto el modelo de mujer propuesto por la aragonesa, ¿nos sentimos defraudados? Es posible. Ideas como la de la importancia de la condición social, la de la supeditación de la mujer al hombre o la de las tareas propias de las mujeres nos parecen, vistas hoy o incluso comparándolas con algunas de las que circulaban a finales del XVIII por Europa, insuficientes y decepcionantes. Pero todo tiene un contexto, en este caso la España de finales del Setecientos, pues, como dice la misma doña Josefa en su Memoria, «es menester confesar que ninguna cosa conocemos en sí misma, sino por comparación con otra» ${ }^{54}$. Comparemos, por lo tanto, las ideas de la ilustrada vistas con algunas de las que circulaban en la Península por entonces.

Lo primero que todos tenemos claro - gracias a alguien con quien siempre estaremos en deuda, me refiero a Jean Sarrailh— ${ }^{55}$, es que en España se podía

$54 \quad$ Ibid., pág. 169.

55 Véase La España ilustrada de la segunda mitad del siglo XVIII, México, Fondo de Cultura Económica, 1957, págs. 15 y ss. 
dividir la población en la masa y en la minoría, y que ésta no era adscribible a un determinado estado social. No hay sino ver la composición de las Sociedades de Amigos del País para darse cuenta de que entre esa minoría había gentes de todo tipo y condición, unas, como observa Aguilar Piñal, por verdadero amor a las Luces, otras por mero afán de medro ${ }^{56}$. En todo caso las elites, los ilustrados, eran sólo unos pocos elegidos —entre ellos nuestra protagonista—, que se empecinaban en intentar que nuestro país saliera de su muy arraigado inmovilismo, el más abominable vicio de los españoles — como lo señaló el hispano-irlandés Ward-, siempre obsesionados por «mantener las cosas en el pie en que las han hallado» ${ }^{57}$. La mínima cantidad de gentes embarcadas en este empeño es lo que ha hecho que estudiosos como Viñao Frago se pregunten si no sería mejor hablar, en el caso español, de ilustrados y no de Ilustración ${ }^{58}$.

En todo caso la estimación que de la mujer se tenía en la época respondía a las coordenadas descritas. Había una selecta minoría, que era consciente de la situación y de la que partirán las ideas que intentarán transformar las mentalidades, y, frente a ella, la masa, capitaneada por aquéllos que vieron peligrar sus intereses por el movimiento ilustrado. Un pueblo que, como ha señalado Fernández Clemente ${ }^{59}$, adoraba las supersticiones, era apático, y abrazaba con unción la idea de preferir lo malo conocido que lo bueno por conocer, es decir, que se decantaba irreflexivamente por lo tradicional, la costumbre.

Es en esta España en la que hemos de imbricar las ideas de Amar y Borbón sobre la mujer, para así poder calibrar su verdadero alcance; en un país en el que desde el Renacimiento se abogaba por la dignificación de la mujer, por su educación, pero siempre con restricciones y todo orientado a los roles de esposa y de madre. Pese a todo, de los cinco millones de españolas que, aproximadamente, había a finales del xviII, sólo un quince por ciento estaba alfabetizada, por lo que el acceso a la cultura era anecdótico ${ }^{60}$. Terreno más que abonado para los contrarios a las nuevas ideas. Allí, con el pulpito y el confesionario como grandes armas, era habitual oír peroratas como éstas acerca de la mujer:

56 Véase F. Aguilar Piñal, «Aragón en el siglo XVIII: predicación y mentalidad popular», Actas del Primer Seminario de la IIustración Aragonesa, Zaragoza, Diputación General de Aragón, 1987, págs. 31-40.

57 Tomo la cita de J. Sarrailh, ob. cit., pág. 18, que procede, a su vez, del Proyecto Económico de Bernardo WARD, Madrid, Ibarra, 1782.

58 Véase A. Viñao Frago, «Ilustración y alfabetización. Notas metodológicas y provisionales sobre una investigación en curso», Educación e Ilustración en España. III Coloquio de Historia de la Educación, Barcelona, Universidad de Barcelona, págs. 353-362.

59 E. Fernández Clemente, La Ilustración aragonesa. Una obsesión pedagógica, Zaragoza, Caja de Ahorros, 1973, págs. 26-27.

60 Véase G. Carnero, «Introducción al siglo XVIII español», Historia de la Literatura Española. Siglo XVIII, Madrid, Espasa-Calpe, 1995, págs. XXV-XXVI. 
...la veréis que, olvidada de la modestia y seducida de aquéllos que siguiendo ciegamente sus perniciosas máximas, se entrega a la libertad, desenvoltura, desahogo, impiedad, gala, pompa y aun una infame prostitución, rompiendo las riendas del decoro, del decir de las gentes, del temor, del escándalo y de su mismo abandono»

Si la cita no se contextualiza, cualquiera pensaría que el sermón del padre Bruno, predicado en 1780 en Zaragoza — contemporáneo, por lo tanto, de nuestra ilustrada-, se refiere a mujeres que cometen los más nefandos pecados. Sin embargo, lo que supuestamente se está describiendo es a la mujer que, simplemente, se deja arrastrar hasta el teatro ${ }^{61}$. No eran infrecuentes consideraciones como éstas, antes bien eran habitualísimas entre los eclesiásticos en un tiempo en el que, hay que tenerlo muy presente, la religión invadía todo y marcaba las pautas de conducta. Pensemos cómo, por ejemplo, el Diario de Zaragoza, que seguramente leería la ilustrada, dedicaba el mayor de sus espacios y cabecera a glosar la vida de un santo en cada número ${ }^{62}$.

Y hay que hacer notar, entre otras cosas, que religiosos y religiosas tenían en sus manos buena parte de la enseñanza del país. Nos cuenta Paula de Demerson cómo la condesa de Montijo, hasta los catorce años, fue educada por las madres salesianas, orden que tenía como mira principal la de formar perfectas casadas, donde la enseñanza de los preceptos religiosos lo vertebraba todo, si bien las aristócratas dotadas podían completar sus estudios con algún acercamiento a las Humanidades ${ }^{63}$. Era exactamente lo habitual en tal tipo de congregaciones: doctrina cristiana, leer, escribir y algo de contar, buenas costumbres y obras y labores propias del sexo. Y si se permitía la lectura, o ésta acompañaba a alguna actividad, los libros habían de ser, indefectiblemente, de índole religiosa. Sólo las «encomendadas» tenían acceso a algo más: latín, romance, ortografía y, tal vez, música ${ }^{64}$.

${ }_{61}$ Padre Bruno, Representación de Juicio a ocasión de haberse incendiado el teatro de comedias en la ciudad de Zaragoza, Ms. Biblioteca Universitaria de Zaragoza, Sig. Caja: 23-536-ar. Véase al respecto, E. Viamonte Lucientes, «Un ejemplo de oratoria antiilustrada: el sermón del padre Bruno al incendio del Coliseo de Zaragoza», en Iglesia y religiosidad en España. Historia y archivos. Actas de las V Jornadas de Castilla-La Mancha sobre investigación en Archivos, Guadalajara, ANABAD, Asociación de Amigos del Archivo Histórico Provincial de Guadalajara y Junta de Comunidades de Castilla-La Mancha, 2002, págs. 1535-1550.

62 Véase Diario de Zaragoza desde enero hasta abril de 1797, «Introducción» de Pedro Alberto Blanco Murillo, Zaragoza, Librería General, 1985.

63 Véase Paula de Demerson, La condesa de Montijo, una mujer al servicio de las Luces, Madrid, Fundación Universitaria Española, 1976.

64 Véase M. LóPEZ ToRrijo, «La formación de la mujer en la Zaragoza del XVIII», Educación e Ilustración en España, Barcelona, Universidad de Barcelona, 1984, págs. 471-485. 
Afortunadamente, entre los eclesiásticos había también notables amigos de las Luces que clamaban por una atención a la condición de la mujer. El célebre Feijoo, por ejemplo, escribe en su Teatro crítico una «Defensa de las mujeres» donde parte de supuestos similares a los de Amar y Borbón: que las mujeres tienen una capacidad similar a la de los hombres y que la educación es capaz hasta de trocar, no sólo entendimiento, sino físico ${ }^{65}$.

En todo caso nos hemos situado de nuevo al otro lado de la orilla, el de los pocos. Los más seguían a pie juntillas las ideas tradicionales. Concepciones como las esbozadas en un curiosísimo manualito titulado Consideraciones políticas sobre marido y mujer, publicado en 1792, escrito "para los hombres prudentes y para aquellas mujeres respetables que, amándose honestamente y con ternura, quieren instruirse en los peligros, desórdenes y escollos que los rodean, para prevenir los daños que de aquí pudiesen resultarles» ${ }^{66}$. En él se dicen lindezas, comunes en la época, como las siguientes: "Casi todas las mujeres tienen la lengua indiscreta: este vicio proviene de su ignorancia», afirmación que se hace en el capítulo V titulado «Medios generales para obligar a ser fieles a las mujeres». Naturalmente, la clave a la hora de elegir mujer es que se busquen siempre «doncellas que hayan sido educadas por padres verdaderamente cristianos», además de que conciten esta otra preciosa condición: «Cuando eligieseis un amigo, buscadlo superior a vos; cuando mujer, inferior, porque de lo contrario os exponéis a casaros con quien os esclavice» ${ }^{67}$. Porque, como se dice en el apartado XI, «no se puede contar mucho con la fidelidad de las mujeres sabias» ${ }^{68}$.

Éstas eran ideas frecuentes que corrían en un manualito popular, al que tenía acceso la población lectora, pero que traduce las creencias habituales al respecto. Ideas que tienen su más perfecta plasmación en un género, la poesía, especialmente en su vertiente popular. Así ocurre en una colección de «Disputas» recogida por otro contemporáneo de doña Josefa, me refiero al ilustrado zaragozano Tomás Fermín de Lezaún ${ }^{69}$. En estas seguidillas se dicen cosas como:

65 Véase P. B. Feijoo, Teatro crítico universal, tomo I, discurso XVI, cito por Madrid, Imprenta Real de la Gazeta, 1779, págs. 192-253.

66 S.A., Madrid, Ramón Ruiz, 1792. Cito por la edición facsímil, Valencia, Librerías París-Valencia, 1993, págs. X-XI.

67 Ibid., págs. 12-13.

68 Ibid., pág. 123.

69 La cita procede de un tomo facticio manuscrito que se conserva en la Biblioteca Universitaria de Zaragoza con la signatura Ms. 387. Véase al respecto Ernesto Viamonte Lucientes, Don Tomás Fermín de Lezaún: la labor creadora y recopiladora de un ilustrado aragonés, Zaragoza, Institución «Fernando el Católico», 2005. 
No quiero dama hermosa,

porque no quiero

estar con su hermosura

siempre en un riesgo.

A lo que el otro le contesta:

Si miras a la fea

dice su cara:

más quisiere mil riesgos

que esta desgracia.

Y en otra:

Yo no la quiero rica

que dice a gritos:

¿tú qué trajiste? nada,

que todo es mío.

A lo mejor porque:

Yo me atengo a la tonta,

que en todo caso

ni sabe ni discurre

lo que yo hago.

Y también:

Yo quiero dama tonta,

que lo entendido

si se busca se encuentra

en cualquier libro.

Libros, esa era la cuestión. Allí estaba el saber, lo que marcaba diferencias, ya lo sabemos, lo vedado para ellas, para las mujeres de finales del xvIII. Lo único que podía abrirles las puertas a un mundo nuevo, como nos cuenta Octavio Paz que le ocurrió a Juana Ramírez de Asbaje cuando descubrió la biblioteca de su abuelo y ya nunca pudo prescindir de lo que allí encontró. Seguramente el más exagerado exponente de una mujer dispuesta a abandonar todo-abrazar todo por su ansia de saber ${ }^{70}$. pág. 117.

70 Véase Octavio PAz, Sor Juana Inés de la Cruz o las trampas de la fe, Barcelona, Seix-Barral, 1989, 
Ahora bien, aun en el caso de que se tuviese semejante ansia por cultivarse, los lastres eran tan tremendos que resultaba complicado seguir adelante. La vida de Sor Juana, aunque con otras coordenadas espaciales y temporales que nuestra ilustrada, es ejemplo extremado. La mismísima Amar y Borbón, única mujer que intervino en la polémica de admisión de damas en la Matritense, tuvo una actuación muy tibia en la otra Sociedad que la acogió, la Aragonesa, como ha estudiado Forniés Casals, entre otros, pues, pese a su traducción de la obra de Llampillas, sólo compareció una vez en ella —en noviembre de 1782 — tomando la palabra para agradecer su nombramiento, si bien es cierto que realizó diversos trabajos para la Económica y que estuvo muy informada de los desvelos de sus socios. Lo mismo ocurrió con otras cuatro féminas que, pese a estar admitidas en la Aragonesa, ni siquiera hicieron Junta de Damas al estilo de la Sociedad de la capital, pese a que se les instót ${ }^{71}$.

Y era aquí, entre los Amigos del País, donde estaban muchos — por no decir todos- de los propulsores de las Luces. Unas Luces que iban de mano de la educación, una educación que debía llegar a las mujeres. Aquí sí tenemos ideas afines a las que hemos visto que esgrimía la autora del Discurso. Campomanes, gran impulsor de las Sociedades, era consciente de la importancia de atender a la condición de la mujer en la época:

Ninguno de los cuidados de las Sociedades Económicas es más urgente que el de examinar los medios de arreglar sólidamente la educación mujeril en nuestras provincias de España ${ }^{72}$.

Aunque también es cierto que entre los mismísimos ilustrados no se mantenía una uniformidad de ideas al respecto. Sirva como ejemplo, que sólo puede entenderse también engarzado a su época, este párrafo de uno de los hombres más admirables del xvIII español, José Cadalso, quien, en sus Cartas marruecas, criticando los pasatiempos y modas a los que se entregaban las mujeres de la época, dice: «¿Quién se ha de casar contigo, si te empleas en estos pasatiempos? ¿Qué marido ha de tener la que no cría hijos a sus pechos, la que no sabe hacerle la camisa, cuidarle en una enfermedad, gobernar la casa y seguirle si es menester a la guerra?» ${ }^{73}$.

Son ideas en plena sintonía con las expuestas en las Sociedades: sí a la educación, pero a una educación que intente lograr una buena madre de familia

71 Véase J.F. Forniés Casals, «Fundación, organización y principales actividades de la R.S.A.A.P. y la participación de Ramón Pignatelli», G. Pérez y G. REdondo (dirs.), Los tiempos dorados. Estudios sobre R. Pignatelli y la Ilustración, Zaragoza, Diputación General de Aragón, 1996, págs. 153-190.

72 Discurso sobre la educación popular de los artesanos y su fomento, Madrid, Sancha, 1775, págs. 379-380.

73 «Carta LXXXVIII», cito por la edición de Joaquín Arce, Madrid, Cátedra, 1989, pág. 297. 
y esposa, donde el factor religioso esté presente y el marbete «labores propias de su sexo» lo presida todo. Sumisión, por lo tanto, al sistema ${ }^{74}$.

Sumamente ejemplificativa es la polémica aludida en la Matritense acerca de la aceptación de damas. Allí hablan a favor de la acogida, entre otros, Manuel José Marín, Campomanes, Jovellanos y la mismísima Amar y Borbón. Pero interviene también, y lo hace abiertamente en contra, Francisco Cabarrús, partícipe activísimo de la Sociedad, autor de obras de marcadísimo talante ilustrado, como sus Cartas sobre los obstáculos que la naturaleza, la opinión y las leyes oponen a la felicidad pública, dirigidas a Jovellanos y dedicadas a Godoy en 1795. Pues bien, Cabarrús, en su Memoria... sobre la admisión y asistencia de las mujeres en la Sociedad Patriótica, dice cosas como que el bello sexo «no se ha contentado con desobedecer las leyes en todas las épocas, sino que a su antojo ha vencido o burlado los legisladores mismos». O que, aunque haya una mujer juiciosa, « ¿cómo podemos disimularnos la petulancia, los caprichos, la frivolidad y las necesarias pequeñeces que son el elemento de este sexo?» Para Cabarrús el papel de las mujeres está en su casa, con sus hijos y marido, y no encuentra un solo objeto «en que sean necesarias o útiles a la Sociedad» ${ }^{75}$.

Cierto es que la postura de Cabarrús no era la de la mayoría de los asociados, pero es significativo que un hombre avanzado en su tiempo tenga ideas como las expuestas sobre el tema que nos ocupa. ¿Cabe, por lo tanto, tildar como alicortas las ideas de doña Josefa sobre el particular? Creo que, al calor de lo visto, se puede afirmar que en absoluto. Eran ideas que iban por delante de las mantenidas por la mayoría de la población, y aun por delante de las esgrimidas por algunos ilustrados, o cuando menos en sintonía con las de éstos. Y además, y espero que no se me malinterprete, eran ideas mantenidas por una mujer en la España de finales del XVII. Directrices en consonancia con su época y con lo que me parece que ha sido la Ilustración española toda: un sí a la renovación, pero sin ruptura, sin abandonar francamente lo viejo. La misma Amar y Borbón nos lo ha dicho: «No formemos un plan fantástico: tratemos sólo de rectificar en lo posible el que está ya establecido».

74 Véase M. López Torrijo, «La R.S.E. Aragonesa y la educación de la mujer», Educación e Ilustración en España. III Coloquio de Historia de la Educación, Barcelona, Universidad de Barcelona, 1984, págs. 264-275.

75 Para esta polémica de la Matritense y para ver las intervenciones al respecto, pues las reproduce, véase Olegario Negrín, ob. cit. El discurso de Cabarrús está en págs. 150-156. 